\title{
Splitting a Difference of Opinion: The Shift to Negotiation
}

\author{
Jan Albert van $\operatorname{Laar}^{1}$ (D) Erik C. W. Krabbe ${ }^{1}$
}

Published online: 12 December 2017

(C) The Author(s) 2017. This article is an open access publication

\begin{abstract}
Negotiation is not only used to settle differences of interest but also to settle differences of opinion. Discussants who are unable to resolve their difference about the objective worth of a policy or action proposal may be willing to abandon their attempts to convince the other and search instead for a compromise that would, for each of them, though only a second choice yet be preferable to a lasting conflict. Our questions are: First, when is it sensible to enter into negotiations and when would this be unwarranted or even fallacious? Second, what is the nature of a compromise? What does it mean to settle instead of resolve a difference of opinion, and what might be the dialectical consequences of mistaking a compromise for a substantial resolution? Our main aim is to contribute to the theory of argumentation within the context of negotiation and compromise formation and to show how arguing disputants can shift to negotiation in a dialectically virtuous way.
\end{abstract}

Keywords Compromise - Fallacy of bargaining - Fallacy of middle ground · Mixed difference of opinion · Negotiation · Resolution

Jan Albert van Laar

j.a.van.laar@rug.nl

Erik C. W. Krabbe

e.c.w.krabbe@rug.nl

1 Faculty of Philosophy, University of Groningen, Oude Boteringestraat 52, 9712 GL Groningen, The Netherlands 


\section{Introduction}

When cooperating with others we need to compromise now and then. ${ }^{1}$ If we want to arrive at a shared decision but cannot convince our peers to go all the way along with us, we need to settle for less than we really prefer: a compromise. A compromise, as we shall elaborate the concept in this paper, is a special kind of agreement based on mutual concessions or sacrifices. Such a compromise will have to result from discussing one or more proposals and their pros and cons. The interpersonal exchange of reasons, or "reasoning" as we shall simply label it in this paper, always plays a vital role in such a dialogue, and since the initial situation of the dialogue is one of disagreement or conflict one may expect this reasoning to be aimed at overcoming the doubts of one's interlocutor, i.e. to have an argumentative function. $^{2}$

For instance, suppose that Bob and Wilma (who live in the Netherlands) are making plans for their vacation. When deciding on their destination, are they going to opt for Bob's proposal to camp on a Dutch island nearby or for Wilma's proposal to stay at a hotel far away at the Algarve? Bob might offer to drop his demand for a vacation on a Dutch island in return for Wilma's sacrifice of her demand for a hotel. In this way, Bob may have created a convincing reason for Wilma, but also for himself, to settle at camping at the Algarve. After all, they might both prefer camping at the Algarve to not having a shared holiday, and the proposed compromise might be seen as striking a fair balance between their diverging wishes as well as being the result of a fair procedure. In such a negotiation dialogue, there is interplay of argumentation and negotiation and elsewhere, we examine this interplay in some detail (van Laar and Krabbe 2016b, Section 4; 2017a). Bob and Wilma differ in their preferences but these differences, by themselves, do not necessarily give rise to any difference of opinion. Yet, in their negotiation process, use is made of argumentation.

Compromises are fashioned also in situations in which the parties do not merely conflict as to their private or partisan interests and preferences, but where they also differ in their opinions regarding the course of action or policy that ought to be adopted. Wilma may not only privately prefer a hotel at the Algarve but also be of the opinion that a hotel at the Algarve would provide for the best possible vacation for both, whereas Bob disagrees and contends that, actually, camping on a Dutch island outcompetes the alternative. In such a situation, there is not only a difference of interest but also a difference of opinion. Typical examples of such hybrid differences can be found among politicians who advance idealistic points of view to defend their preferred choice of policy.

Compromises may even be the intended outcome if the participants do not have conflicting private or partisan interests, but only a difference of opinion. Take, for instance, two parents disagreeing on what would be the best way to raise their

\footnotetext{
1 An earlier version of this paper has appeared as Sections 1, 2, and 3 of van Laar and Krabbe (2016b).

2 In our survey of the functions of reasoning (Krabbe and van Laar 2007, pp. 28-31), we proposed to use the term "argumentative function [of reasoning]" in the sense of being "used in some kind of conflict in order to overcome doubt of an interlocutor" (p. 31).
} 
children: Should John go to a Christian private school or to a secular public one? Should Mary be allowed to go to this friend's party? In each case neither parent may be able to convince the other; even so they could solve the problem by a compromise that is not motivated by any other concerns than the child's well-being and a prompt decision. Thus, discussants who are unable to convince their interlocutors of the objective worth of action proposals are sometimes willing to search instead for a compromise that each may conceive as only a second choice, but fair and preferable to a lasting conflict.

In this paper, we are particularly interested in dialogues about an action proposal in which the participants shift from a persuasion dialogue about the proposal's merits, towards a negotiation dialogue in which they aim at splitting their difference of opinion in a reasonable way. Though some work has been done within argumentation studies on the norms for shifting from persuasion dialogue to negotiation dialogue (Walton and Krabbe 1995; Wells and Reed 2003), a dialectical account in terms of how to justify such a shift to a skeptical interlocutor requires more detail. The emphasis in our account is on the feasibility of making such shifts in a dialectically reasonable manner but in this connection we think we should also take into account that there are pathological shifts and to that end discuss the Fallacy of Bargaining (cf. Walton and Krabbe 1995, p. 104).

We further want to contribute to the theory of argumentation by investigating the difference between resolving and settling a difference of opinion. In our view, a study of the connections between argumentation and negotiation requires an account of the concept of a compromise that is explicit about how it relates to the resolution of differences of opinion. Though within dialectical argumentation theory some steps have been taken in this direction (Walton 1998, Chapter 4; van Eemeren and Grootendorst 2004, pp. 57-58), again, a sufficiently detailed account is not yet to be found. Dialogue participants may possibly be less clear-headed about the distinction than their dialogue requires, and thus, again, we take into account that there are pathological cases, this time under the heading of the Fallacy of Middle Ground.

The two sections that follow deal with two questions. (1) What reasons might warrant a shift from a persuasion dialogue to a negotiation dialogue; and under what conditions would such a shift from persuasion dialogue to negotiation dialogue be a licit shift, rather than a fallacious one? (2) What is the nature of a compromise, in contradistinction to a resolution? In follow-up studies, we examine the role of arguments within the context of negotiation and compromise formation (van Laar and Krabbe 2016b, Section 4; 2017a), as well as the criticism and defense of compromises vis-à-vis supporters and others who have not been actively participating in the construction of the compromise solution (van Laar and Krabbe 2017b).

\section{Reasons to Shift from Persuasion Dialogue to Negotiation Dialogue}

A natural setting for initiating a negotiation dialogue, though certainly not the only one, is the situation that occurs within a persuasion dialogue when both parties have attempted but failed to convince the other of the acceptability of one's own favorite policy option. When developing our views on the shift to negotiation, we start from 
the theory of dialogue types, as developed by Walton and Krabbe (1995). A persuasion dialogue, then, is the kind of dialogue that starts from a difference of opinion and in which the participants try to convince one another of their standpoint by appealing to reasons that the other side is willing to concede, doing so in a cooperative endeavor to resolve their difference of opinion on the merits of both sides (Walton and Krabbe 1995, Section 3.1; Walton 1998, Chapter 2; van Eemeren and Grootendorst 2004, Chapter 6). The failure to find a resolution may prompt the parties to shift to a negotiation dialogue, which is a dialogue that starts from a difference of interests or from a difference of opinion (see Introduction) and in which the participants aim at getting as much as possible what they want, doing so in a cooperative attempt to strike a deal (Walton and Krabbe 1995, Section 3.1; Walton 1998, Chapter 4). What would be good reasons to make this shift from persuasion dialogue to negotiation dialogue, and under what conditions would such a shift be a licit shift, rather than a fallacious one ${ }^{3}$ Before we come to these questions we will elaborate on persuasion dialogues starting from a mixed difference of opinion (i.e. a difference of opinion in which both parties have expressed a standpoint) about policies or action proposals. For these are the kind of persuasion dialogues that naturally could shift to a negotiation dialogue.

\subsection{Resolving Mixed Differences of Opinion About Action Proposals}

Let us assume that party A and party B have advanced opposing positions regarding the policy they should adopt in order to respond to a social problem or contingency: party A contends that the best response would be to adopt policy Alpha, whereas party B favors policy Beta but adoption of policy Alpha would be incompatible with adoption of policy Beta. Let the thesis defended by party A be that they should adopt policy Alpha and consequently not policy Beta (proposition $a$ ). Let the thesis defended by B be the contrary (but not necessarily contradictory) proposition to the effect that they should adopt policy Beta and consequently not Alpha (proposition b).

Let us illustrate the situation by means of an example. In 2012, two Dutch political parties, the Labor Party (PvdA) and the Liberal Party (VVD) agreed to form a coalition government. Part of their agreement dealt with renewable energy. As a starting point, the Labor Party (party A) proposed that the level of renewable energy be increased to $18 \%$ in 2020 (policy Alpha), whereas the Liberal Party (party B) favored a policy of increasing the level of renewable energy to just $14 \%$ in 2020 (policy Beta) (Visser 2012).

Now let us further assume that party $A$ and party B engage in a persuasion dialogue in which both parties seriously try to convince the other of the superiority of one's own preferred policy and thus to resolve their difference of opinion. How must we apply the notion of a resolution of a difference of opinion in the present

\footnotetext{
3 When two parties choose to engage in a dialogue of a specific type, they commit themselves to contribute to the realization of the main goal of that type of dialogue type. We assume that such a choice brings particular dialogical obligations. Thus, a shift to a different dialogue type can be the subject of normative evaluation.
} 
case of a mixed difference of opinion, and what kind of outcomes plausibly give rise to a shift to negotiation dialogue?

Van Eemeren and Grootendorst defined the notion of "resolution" for non-mixed differences of opinion, where a protagonist defends one standpoint and an antagonist takes a position of critical doubt yet without adopting an opposed standpoint of her own. In such a situation, the difference of opinion is said to have been resolved either "when the arguments advanced [by the protagonist] lead the antagonist to accept the standpoint defended, or when the protagonist retracts his standpoint as a consequence of the critical reactions of the antagonist" (van Eemeren and Grootendorst 2004, p. 133). But here we are dealing with a mixed difference of opinion in which each of the two parties takes the role of protagonist regarding its own standpoint (party A defending standpoint $a$, party B defending $b$ ) and the role of antagonist regarding the other party's standpoint. Therefore there are two non-mixed differences involved and we need to check what outcomes of the persuasion dialogue are now possible and which of them we would want to call resolutions, either fully or partially, of the mixed difference of opinion composed of these two non-mixed differences. In particular, we are interested in those outcomes that would naturally lead to a shift to negotiation.

At the end of a persuasion dialogue between parties A and B, each party may either maintain its standpoint or retract it, also each party may either maintain its critical stance towards the standpoint of the other or retract its critical stance, i.e. concede the standpoint of the other. But since the propositions $a$ and $b$ are (we presume: manifestly) incompatible, we may exclude that a party maintains its own standpoint and concedes the contrary standpoint of the other. Therefore, for each party there are only three instead of four possibilities:

(1) a party (say party A) maintains its standpoint (maintains $a$ ) and maintains its critical stance towards the contrary standpoint of the other (criticizes $b$ );

(2) party A retracts its own standpoint (retracts $a$ ) as well as its critical stance towards party B's standpoint, thereby conceding the latter (concedes $b$ );

(3) party A retracts its own standpoint (retracts $a$ ) yet sees no reason to retract its critical stance towards party B's standpoint (criticizes $b$ ).

Similarly, there are three possibilities for party B, which yields nine possible outcomes. Of these nine possible outcomes, three may count as "full resolutions".

Full resolution:

(Outcome (i):) If party A acts according to (1) and party B according to (2), the mixed difference of opinion will have been fully resolved in favor of party A. (Outcome (ii):) If party A acts in according to (2) and party B according to (1), the mixed difference of opinion will have been fully resolved in favor of party B. (Outcome (iii):) If both parties act according to (3), the mixed difference of opinion will have been fully resolved, partly in favor of party A and partly in favor of party B.

Outcome (iii) differs from the other two in that, even though the differences of opinion are resolved, there is now no action proposal left to be adopted. This situation would, so we think, give naturally rise to a deliberation dialogue, which 
starting from an open problem of a practical nature (and, differently than a persuasion dialogue, not from some kind of conflict), allows the participants to explore new policy options (Walton and Krabbe 1995, pp. 73-74).

A persuasion dialogue arising from a mixed difference of opinion, which is composed of several non-mixed differences of opinion, results in, what we call, a "partial resolution" if some of its non-mixed differences of opinion are resolved but others not. For instance, (outcome (iv):) party A acts according to (1) and B according to (3), for though the difference of opinion about $b$ gets resolved in favor of party A, the difference about $a$ remains unresolved. Another case of partial resolution is where (outcome (v):) party B acts according to (1) and party A acts according to (3).

We shall say that a non-mixed difference of opinion about standpoint $s$ is "weakly resolved" if at the end of the persuasion dialogue the proponent retracts $s$ whereas the opponent concedes it. In three possible outcomes of the persuasion dialogue between party $\mathrm{A}$ and party $\mathrm{B}$, at least one of the component non-mixed differences of opinion is only weakly resolved: (outcome (vi):) If A and B both act according to (2), so that both differences of opinion are weakly resolved; (outcome (vii):) A acts according to (2) and B according to (3), so that issue $a$ gets resolved in favor of party B but issue $b$ gets resolved only in a weak sense; (outcome (viii):) A acts according to (3) and B according to (2), so that issue $b$ gets resolved in favor of A but issue $a$ gets resolved only in a weak sense. ${ }^{4}$

The outcome that most naturally gives rise to a shift towards negotiation (though a shift to deliberation is never excluded) is where (Outcome (ix):) party A and party B both act according to (1), so that they each maintain their own standpoint and their critical stance towards the standpoint of the other and no progress is made towards resolution, except for possibly gaining a better understanding of the issue. When it has become obvious that a persuasion dialogue only leads to a stalemate, it is less opportune to start another persuasion dialogue and perhaps time to look for other ways to make progress. Here the negotiation dialogue is an obvious candidate. So, when the discussion is deadlocked on whether to increase the level of renewable energy to $14 \%$ or to $18 \%$, the parties may try to negotiate a middle ground position, such as by splitting the difference at $16 \%$. The outcomes (iv)-(viii) would, we think, like Outcome (iii) give most naturally rise to a deliberation dialogue,. The reason is that with these outcomes, either none of the parties maintains any standpoint (outcomes (iii), (vi), (vii), and (viii)) or one of them does not maintain one (outcomes (iv) and (v)), so that a proper starting point for negotiation is lacking. Rather one or both participants may be motivated to search for what it might regard

\footnotetext{
4 A weak resolution occurs when the proponent is convinced by the opponent's criticism and the opponent by the proponent's arguments. It is close to swapping positions. Yet it differs in two respects: retracting one's standpoint is short of taking a critical stance toward one's former standpoint and conceding the standpoint of the other is short of asserting it and making it one's own standpoint. When a weakly resolved dispute would swing to a full swapping of positions, the parties may naturally re-open a persuasion dialogue in which they each defend their newly acquired standpoint against their newly acquired critic. Thus, in some spectacular cases the outcome (see Outcome vi in Table 1) may prompt a mixed persuasion dialogue, based on a two-fold swapping of the roles of proponent and opponent, whereas other outcomes (see Outcome vii in Table 1) and (Outcome viii) may prompt a non-mixed persuasion dialogue, based on a single swapping.
} 
Table 1 The possible outcomes of a persuasion dialogue arising from a mixed difference of opinion (party A's standpoint being $a$ and party B's standpoint being $b$ )

\begin{tabular}{llll}
\hline Outcome & Party A's final stance & Party B's final stance & Type of outcome \\
\hline i & (1) Maintaining $a$; criticizing $b$ & (2) Retracting $b$; conceding $a$ & Full resolution \\
ii & (2) Retracting $a$; conceding $b$ & (1) Maintaining $b$; criticizing $a$ & Full resolution \\
iii & (3) Retracting $a$; criticizing $b$ & (3) Retracting $b$; criticizing $a$ & Full resolution \\
iv & (1) Maintaining $a$; criticizing $b$ & (3) Retracting $b$; criticizing $a$ & Partial resolution \\
v & (3) Retracting $a$; criticizing $b$ & (1) Maintaining $b$; criticizing $a$ & Partial resolution \\
vi & (2) Retracting $a$; conceding $b$ & (2) Retracting $b$; conceding $a$ & Weak resolution \\
vii & (2) Retracting $a$; conceding $b$ & (3) Retracting $b$; criticizing $a$ & Partial and weak \\
viii & (3) Retracting $a$; criticizing $b$ & (2) Retracting $b$; conceding $a$ & $\begin{array}{c}\text { Partial and weak } \\
\text { resolution }\end{array}$ \\
ix & (1) Maintaining $a$; criticizing $b$ & (1) Maintaining $b$; criticizing $a$ & No resolution at all \\
\hline
\end{tabular}

as a proper response to the policy issue at hand. A deliberation dialogue is befitting such a setting. ${ }^{5}$ We summarize the nine outcomes in Table 1.

\subsection{Reasons for a Shift to Negotiation}

We suppose now that, at a certain point in their persuasion dialogue, the parties, A and $\mathrm{B}$, have made serious attempts to convince the other but that no full resolution has been realized. Further, we suppose that party A does not expect that this persuasion dialogue will ever result in a full resolution nor that a different persuasion dialogue about a somewhat different policy proposal, for instance one generated in a deliberation dialogue, will succeed in that sense. Next, we suppose that at this point party A proposes to abandon the persuasion dialogue and to turn to a negotiation dialogue aimed at reaching some compromise. Party A may table such a proposal explicitly but can also do so more implicitly; for example, it may just launch the negotiation dialogue by making a quid pro quo move: "If you would mitigate your demands regarding policy Alpha (for example by accepting a level of renewable energy of $16 \%$ in 2020 , rather than only $14 \%$ ), we would be willing to mitigate our demand for rejecting policy Beta (for example by accepting a level of $16 \%$ in 2020 rather than the full $18 \%$ )". In order to examine the dialogical possibilities in more detail, however, we finally suppose that party A before making a first offer, tables an explicit proposal to pursue their conversation in another way: "We propose that we abandon our persuasion dialogue on this issue and initiate a negotiation dialogue in order to find out whether we can agree on some compromise". In Sect. 3, we shall examine in more detail the nature of a compromise (the kind of outcome party A allegedly has in mind when trying to shift to negotiation dialogue) and how that kind of outcome compares to the resolution of

\footnotetext{
5 If, then, the deliberation dialogue generates a policy Gamma, disagreement may in turn arise over the desirability of that new policy proposal, and the parties can try to resolve the issue within a new persuasion dialogue, about the acceptability of a new standpoint (proposition $c$ ).
} 
a difference of opinion aimed for in persuasion dialogue. For now it suffices to start from the assumption that by proposing to shift to a negotiation dialogue, party A proposes to work together on developing an agreement based on mutual sacrifices. ${ }^{6}$

In such a situation, what might be the reasons for party $A$ to propose the shift, and how may party A convince party B to accept such a proposal? After all, party A cannot take it for granted that party B considers some sort of agreement about the policy issue as intrinsically better than a lasting disagreement about it. We examine this issue in a dialectical vein by listing a number of answers party A may advance in response to the challenge that we imagine party $\mathrm{B}$ advances in response to the proposal: "Why shift thus?" and by pointing out some further considerations with which the parties can test the adequacy of the reasons offered by Party A for shifting thus.

The principal reason for shifting away from persuasion dialogue, as well as from further deliberation about alternative policy options and persuasion dialogues about these options, is the expectation that the persuasion dialogue's common goal of resolving differences of opinion is not realizable for the issue under discussion and that consensus is therefore out of reach. Possibly, in party A's estimation, all available options and considerations have been advanced, without there being any prospects for gaining further insights about the position of the other or about the issue at hand, let alone for resolving the present difference of opinion. Apparently, party B finds no reason to budge, and neither does party A. "A full resolution is beyond reach and dragging out the persuasion dialogue would not serve any purpose", so party A may claim in order to justify to party B its proposal to abandon the current persuasion dialogue.

But why turn to negotiation, rather than to another type of dialogue, such as an eristic one, or to a non-discursive device for ending the dispute, such as having a vote on the matter, or throwing the dice? The possible answers we here attribute to party A and the responses we attribute to party B are inspired by a discussion between Simon Căbulea May (2005) and Daniel Weinstock (2013). ${ }^{7}$ In his paper, May defends that political compromises can, depending on the situation, be justified by means of, what he labels, pragmatic reasons. One has a pragmatic reason to compromise if the existence of disagreement makes it unlikely that one's political or moral aims can be realized whereas it is likely that a compromise would enable one to realize one's aims at least to a certain extent (May 2005, p. 320). May conjectures that "moral compromise in political life is only ever warranted for pragmatic reasons" (May 2005, p. 317). Weinstock, however, contends that there are also principled, moral reasons for compromise, namely, reasons appealing to the existence of dissenting peers that do not boil down to pragmatic reasons (Weinstock

\footnotetext{
${ }^{6}$ Political negotiation processes can be conceived as involving a shift from persuasion dialogue to a negotiation dialogue in so-far as the parties concerned acknowledge that their earlier attempts to persuade one another have failed. For example, it is because no consensus had been realized about how to balance diverse policy preferences concerning the limits to be set on the rise of temperature, with compensations for poor countries and with transparency measures, that the United Nations called for the negotiations that resulted in the Paris Agreement on Climate Change in 2015.

7 The discussion between May and Weinstock concerns the related, but somewhat different issue, whether there are principled reasons for accepting a particular compromise.
} 
2013, p. 538). What May labels "pragmatic reasons", Weinstock generally calls "strategic arguments". But Weinstock seems to assemble some of the reasons that May would include as "pragmatic reasons" in a class of "arguments from principled consequentialism" and thereby to assign them a special moral status (Weinstock 2013, p. 553). In order to justify its proposal to shift to a negotiation dialogue, our party A draws upon the justificatory resources provided by Weinstock. Party B engages critically with these justifications, making use of the more skeptical considerations about principled compromise advanced by May.

Party A then finds five reasons for compromising: a strategic (pragmatic) reason and four more principled reasons. ${ }^{8}$ We list them below, labeling them in line with Weinstock's nomenclature. We also provide a sketch of a number of plausible dialectical exchanges, thereby elaborating on the idea of having available good, convincing reasons to shift from persuasion to negotiation dialogue.

(1) The strategic argument

Party A may justify its proposal to party B, saying: "By arguing you achieve nothing. By negotiation you achieve at least something”. Party A explains to party B that a mutually agreed upon compromise will admittedly not provide either of them with its favorite policy but with a policy that, though second-best, will—given the personal or partisan interests of both parties-yet be preferable to a lasting disagreement (see May 2005, p. 319; Weinstock 2013, p. 541). The positive consequences appealed to can be quite diverse, and include a commonly accepted policy, the termination of a disruptive dispute, or simply profiting from the yields of cooperation. Typically, time pressures the interlocutors to opt for negotiation (and to abandon persuasion dialogue) when the parties need to coordinate swiftly to avoid harm or to take advantage of an opportunity. Thus, or so party A may claim, it's prudent to shift to negotiation. (And if desired, they can return to the initial persuasion dialogue at a later, calmer moment, more suitable for reflection.)

This line of reasoning could convince party B. But then, party B may express its qualms about it. Party B may assess the situation differently, and if this party is unable to compromise or does not assume that a compromise is going to result, or at least not an outcome that is preferable to the situation that will result when no deal is made, it can be expected to reject the proposal. A special version of this objection that B may advance is that an agreed upon compromise will require the violation of a principle that $\mathrm{B}$ regards as non-negotiable. Margalit, for instance, although pleading for a spirit of compromise in international affairs, and even defending some unjust compromises for the sake of peace, stops short of the moral acceptance of compromises that include "an agreement to establish or maintain an inhuman regime, a regime of cruelty and humiliation" (Margalit 2010, p. 2). Note that the appeal to non-negotiable principles can also serve as a response to any of A's other reasons, discussed below.

\footnotetext{
8 The last three of these five kinds of reasons are also available beyond a setting where a persuasion has failed or is doomed to fail. We thank an anonymous referee for this observation.
} 
(2) The argument from principled consequentialism

Party A may justify its proposal, saying: "It would just be wrong to neglect the possibility of realizing at least part of your aims". Weinstock argues that a costbenefit analysis can also be considered to provide a principled reason in support of compromise. He stresses the principled motivation for developing a compromise if the latter is considered to advance one's moral aims (Weinstock 2013, pp. 552-554). After all, the outcome may promote cherished values or purposes of the parties, such as the value party A attaches to the implementation of green policies and party B's purpose of keeping public expenditure low. Thus, party A may answer party B's challenge by pointing out that a motivation for entering a negotiation dialogue is provided by the moral ideas and political ideals that party $\mathrm{B}$ itself embraces.

Again, party B may agree, but it may also assess the situation differently and object that the profits from entering the negotiation dialogue, even if some of these are moral profits, will not weigh up against the kind of concessions it will be required to make.

(3) The epistemic argument

Party A may justify its proposal, saying: "Neither of us can be sure of having a complete view of all aspects of the situation and a deal might do justice do a wider array of considerations". Party A thus advances an epistemic reason for exploring the possibility of a compromise-without withdrawing its firm commitment to policy Alpha as its first preference. This reason could justify a negotiation dialogue even if one of the contesting parties is in a position to foist its favorite policy option upon the other side. For each of the parties may come to acknowledge that because of the complexity of the issue at hand, the policy it favors will, as a matter of fact, run a risk of not taking adequately into account all relevant considerations. By compromising, one could do justice to one's own epistemic fallibility (see the critical discussion of this consideration by May 2005, pp. 338-340), especially if one strives for a compromise that integrates various aspects of the parties' favored policies (rather than replacing the initial proposals by a quite different third policy) so that a broader range of considerations will get incorporated in the outcome. If during the negotiation dialogue one keeps an eye on avoiding the inclusion of those aspects of these policies that are flawed or mistaken, the result will plausibly be less prone to error and one-sidedness (see Weinstock 2013, pp. 545-548).

Party B could acknowledge that an outcome is more firmly justified if it integrates components of the proposals of both parties. Instead, however, party B may advance the following objection to party A's proposal: If you would be interested in an outcome that is based on a broader range of considerations, it would be more sensible to initiate a deliberation dialogue, in which we both explore possible improvements, instead of a negotiation dialogue. After all, the outcome of negotiation may turn out to be more one-sided than desirable, for example by no longer duly promoting the interests of some of the stakeholders. 
(4) The democratic argument

Party A may also justify its proposal, saying: "Making a deal with contributions from both sides is more democratic than a one-sided solution". A party may opt for a negotiation dialogue for the reason that a compromise would reflect at least some of the opinions or interests of both interlocutors. Thereby, a compromise outcome can be seen as having a democratic merit. Party A, then, can try to convince party B to accept the proposal to shift to a negotiation dialogue by an appeal to party B's democratic concern for letting not just its own views but also at least some of party A's views be reflected in the outcome of their discussion. Party A may add that the outcome of a persuasion dialogue may be skewed towards those who are wellequipped with persuasive skills and that there is reason to correct for such a procedural bias by making a concession to parties that are unable to get things their way by means of a persuasion dialogue (see Weinstock on compensating for biases in democratic procedures, 2013, pp. 548-551).

Party B may share this democratic concern. It may, however, instead reject the idea that democracy ought to produce middle-of-the-road policies that contain something for each and all. Also, party B could table a counterproposal for the improvement of the current procedures for persuasion dialogues. If party A has any specific reasons to think that the rules of the persuasion dialogue unduly favor one side or the other, this information can be used to improve the procedure along the way (see Weinstock's version of this reply, which pertains to democratic decision making procedures, 2013, pp. 549-550). An attempt to improve the setting for persuasion dialogue, so party B advances, is more fruitful than a shift to negotiation dialogue: Concessions made within negotiation dialogue are likely to be ad hoc and not systemically directed at neutralizing the bias at hand and they need not result in an improved outcome.

(5) The community-based argument

Finally, party A may justify its proposal, saying: "To compromise would help to build a community". In this way, party A tries and persuades party B to shift to a negotiation dialogue by pointing out that a compromise fosters a relationship among them that is based on mutual concern rather than on a winner-takes-all mentality. It would be mutually generous if they would aspire at a compromise that includes preferences from both sides (see Weinstock 2013, pp. 551-552).

Party B may be susceptible to this appeal to its appreciation of this kind of community, even if this means conceding something to party A. Of course, it may also be the case that party B doesn't mind a winner-takes-all mentality and makes it clear that it prefers a political culture where the winner gets a real chance of implementing its favored policy to a political culture of moderation in which controversy is avoided.

These five arguments show that party A has various options for motivating a shift to negotiation dialogue, so that this party has quite some means for trying to win over party B to accept its proposal if the latter party would be hesitant to make the 
shift. Of course, party B may not be persuaded by party A's reasoning - in which case their dialogue will probably take a different direction.

Walton and Krabbe (1995) have dealt with the procedural requirements for making licit dialogical shifts, rather than fallacious ones. About the shift from persuasion dialogue to negotiation dialogue they write:

Sometimes it may be better to close off the persuasion dialogue and try to settle the matter by negotiation or some other means. The problem is that often the persuasion dialogue isn't closed off properly at all and the shift occurs without both participants being aware of it and agreeing to go along with it. (Walton and Krabbe 1995, p. 110)

When one party initiates such an illicit shift from a persuasion dialogue to a negotiation dialogue it is said to commit the Fallacy of Bargaining (substituting offers for arguments, p. 104), and the receiving side is hindered in its attempt to realize the goal of the type of dialogue in which it was supposed to be engaged, i.e. the goal of resolving a difference of opinion within the setting of a persuasion dialogue.

However, we can assume that when party A makes an explicit proposal to party B to abandon their persuasion dialogue on a policy issue and to shift towards a negotiation dialogue about that issue, this party tries to close off the persuasion dialogue in a proper manner. What is more, party A prepares for the start of a negotiation dialogue in a way that is fully transparent to its interlocutor. If party B then, implicitly or explicitly, agrees to shift, possibly after having been offered good reasons for shifting thus, the fallacy of bargaining will not have been committed even though the parties now become engaged in quite a different conversational setting. In our view, the fallacy of bargaining is also avoided by party $\mathrm{A}$ if this party tries to shift from persuasion to negotiation in less wordy and explicit ways, for example by simply making party B an offer, if only the underlying message and its implications are within the context of utterance sufficiently clear to party B, so that party B gets the opportunity to refuse to go along with the implicit proposal to shift to negotiation.

\subsection{Worries About Turning to Negotiation}

Granted that there are these ways to justify a transition from persuasion to negotiation dialogue, one may still have a lingering worry about whether shifts from persuasion dialogue to negotiation dialogue can ever be legitimate in "contexts where epistemic considerations are relevant", as David Godden has put it (Godden 2016 , p. 3). In Godden's view, “what is at issue in epistemic contexts are the rational merits of competing claims and these are not the sorts of things that can be gained through bargaining or traded away" (p. 4). He illustrates his view by the case of a divorcing couple fighting over the custody of their children, where each claims the other to be an unfit parent. If a mediator succeeds in negotiating a shared custody "such a settlement ought to be manifestly unacceptable to any rational, third-party judge" (Godden 2016, p. 5), because such an outcome should be acceptable only if both parents are acknowledged as fit parents. Consequently, the parents can only 
rationally agree to any such compromise if they first resolve the fitness issue and agree that both of them are as a matter of fact fit parents. The fitness issue, however, can presumably not be settled by negotiation.

Our account of splitting differences of opinion deals only with situations in which the participants have to make a practical decision, and we agree with Godden that our account cannot, without further ado, be applied to settings that lack a practical aspect. ${ }^{9}$ Practical issues, however, may depend on subordinate issues of a factual or theoretical nature, such that the participants would have resolved their practical issue as soon as they were to resolve these "epistemic" issues. ${ }^{10}$ Also for such cases, we contend that the parties may turn to compromise, in at least some settings (our response to Godden can be found in van Laar and Krabbe 2016c).

Take for instance a policy debate on whether to adopt a particular set of measures in order to keep the average temperature from rising more than two degrees on the scale of Celsius. Suppose that the parties embrace the same climate goals and that they all prefer economic over spendthrift policies. Suppose further that one party believes that these measures are required and sufficient to bring about the intended effect whereas the other party expects that these measures would not suffice and that costly additional measures are needed. Then only a factual or theoretical issue underlies the policy dispute. Nevertheless, we take it for granted that in such a situation, the parties may have legitimate reasons to split their difference of opinion, and to inquire into the possibility of modifying the set of measures, possibly by adding some of the proposed additional costly measures but not all of them. For by doing so, each party attempts to realize most, yet not all, of what it considers an appropriate balance between effectiveness and efficiency. That a disputed proposition is factual or theoretical does not and should not keep parties from adopting a compromise. Godden may object that "any rational, third-party judge" would reject the outcome, for example because it has not been established that the agreed measures suffice to save our world from climatological disaster, or because it has not been excluded that they would lead to an economic disaster. If both disputants acknowledge this judge as completely rational and neutral, we agree that they have reason to go along with this judge's judgments. However, for most controversies, no such judges are available or disputants disagree over who could act as a rational and neutral judge. When the participants are left to their own devices but unable to convince one another on substantial grounds, they would, we think, be better off if they shifted to negotiation: Negotiation may help them to arrive at a policy that, from the viewpoint of each of the competing parties, is at least to be preferred to not adopting any common policy at all and that, moreover, is optimal in the sense of not admitting an improvement that would be acceptable to all competing parties.

In addition to the case of the divorcing couple, Godden advances plea bargaining as a context where dialogue shifts from persuasion to negotiation confront "a moral

\footnotetext{
${ }^{9}$ Note, however, that even a scientific discussion may have a practical aspect, which could make it opportune to compromise. When co-authoring a handbook chapter, or a scientific dictionary, or a research proposal, collaborating authors that disagree on how to characterize some theory or define a term may each be willing to make a concession in order to finish their task in time.

${ }^{10}$ In the case of the divorcing couple the resolution of the underlying theoretical fitness issue does presumably not yet imply a resolution of the practical custody issue.
} 
hazard" (p. 5). We agree that much plea-bargaining is likely to have very unwelcome effects. Prosecutors may profit from their being better informed and from the fact that they are in a position to manipulate and push the defendant into going along with concessions that are unwarranted and unjust. Yet, this does not exclude other plea bargaining situations where the risk confronted by shifting to negotiation is much reduced, for example by providing assistance to vulnerable parties, by excluding criminal offenses, or by banning particular kinds of pressure or threat. In some situations, existing risks may be compensated by welcome effects. So, we think that plea-bargaining would provide an excellent domain for studying social restrictions on shifts from persuasion to negotiation dialogue, which is a topic that we have thus far left aside.

In this section we saw that there can be good reasons available for the discussants to shift from a persuasion dialogue to a negotiation dialogue and that discussants may carry out such a shift in a licit manner. A licit shift from persuasion dialogue to negotiation dialogue completely changes the nature of the conversation. After the shift, the main goal of the dialogue is different: No longer will the parties attempt to resolve their conflict; instead they try to settle it by compromise. Yet the ultimate goal still consists in a kind of agreement. How does the agreement found in a compromise differ from that found in a resolution? This issue will be dealt with in the next section.

\section{The Nature of a Compromise}

What is the nature of a compromise, and how is a compromise different from an outcome that qualifies as a resolution? This section deals with the sense in which participants can settle their difference of opinion by means of compromise. In our view, a compromise that settles a disagreement is different from a resolution of that disagreement, even though it is connected to the resolution of related but different disagreements. When the socialist party A and the liberal party B persist in disagreeing with one another about the policy to be preferred and commence a negotiation dialogue, it will be expected that a successful outcome will consist of a compromise that lies "somewhere in the middle" between the original positions of these parties. However, parties may mistake a compromise where the outcome is "somewhere in the middle" for a regular resolution of the policy issue. For example, when the accuser pleads that the accused deserves to be put behind bars for a full year, yet the accused pleads innocence, parties may conclude and agree that the accused really deserves to be sentenced to half a year. But is this a resolution or a compromise? It can be a resolution only if it is based on argumentation that is fully convincing for both parties. We label the mistake of presenting a compromise as a regular resolution, either to oneself or to others, the Fallacy of Middle Ground. ${ }^{11}$

We start from the following definition of "compromise" offered by Weinstock:

\footnotetext{
11 There is not much literature to be found on the Fallacy of Middle Ground but there is a Wikipedia entry devoted to the Fallacy of Moderation that broaches the subject (Wikipedia 2016).
} 
At a first approximation, a compromise is a position that, with respect to the issue at hand, is from the point of view of parties locked in debate or negotiation inferior to the positions that both (or all) bring to a decision making process (a negotiation, an election, or more trivially a decisionoriented discussion among friends), but which both have reason to accept instead of the position they favor. They may favor X, when only the issue at hand is in view, but favor $\mathrm{Y}$ when all things are duly considered (Weinstock 2013, p. 539).

Instead of conceiving a compromise as some kind of position, we prefer to amend the definition so that a compromise is a kind of agreement that concerns an arrangement that for each competing party is inferior to their initial positions yet which they have reason to accept in the social setting at hand. We shall try to provide further clarification by highlighting five features of compromises:

First, as we said, compromise is not resolution. A compromise about a policy implies that the parties to the compromise still favor their initial policy proposals and that they only subscribe to the compromise for the reason that each of them happens to be unable to realize the adoption of its own preferred policy. No compromise is without mutual concessions, in the sense of sacrifices. ${ }^{12}$ Thus, we do not speak of a compromise in a situation where the parties come to acknowledge strong features of one another's positions, and where they change their minds about what policy to pursue, even if the resulting consensus concerns a more intermediate, middle-of-the-road policy than the preferred positions with which the parties entered the conversation. As Benjamin writes: "Strictly speaking, a compromise does not end the disagreement" (Benjamin 1990, p. 7).

Second, compromise is not imposed. A compromise is subscribed to in a sufficiently free and autonomous manner, and is the outcome of a sufficiently noncoercive process. ${ }^{13}$ After all, reaching a compromise counts as an outcome that is based upon the parties' decisions. (If one speaks of a "compromise" also when a deal is imposed by one's opponent, or by a third party, as a kind of dictate, the expression is used in a much broader sense than the sense that we attach to it.) On the other hand, some measure of pressure and even threat is inherent in negotiation dialogue, which is a standard device for developing compromises. Some kinds of threats seem to be an admissible part of negotiation dialogue, depending on specifics of context, and within constraints, but we must admit that we do not dispose of a detailed normative theory for negotiation dialogue that specifies the rights and duties for the participants (see for a dialogue protocol in which threats, and rewards, are instrumental for finding a compromise: Amgoud and Prade 2006). One general constraint must be that the pressure does not spoil the cooperative process. Among the prima facie acceptable ways of pressuring in negotiation dialogue we include the

\footnotetext{
12 Note that "concession" may also be used to refer to the kind of propositional commitment with which one forgoes one's right to challenge a proposition, yet without incurring an obligation to defend it, if so requested. This usage is the more central one in accounts of persuasion dialogue (Walton and Krabbe 1995, pp. 186-187).

13 This constraint is related to the requirement, discussed in the context of public controversy, according to which conversational strategies ought to be tolerant (van Laar and Krabbe 2016a).
} 
negative message suggested by a quid pro quo move- "If you don't accept the concession I request I won't accept yours" as well as the threat to abandon the negotiation process. The outcome must, however, count as a result of free choices, rather than of intimidation. Further, when we evaluate threats, we must take into account the norms and conventions that happen to govern the communicative practice in which the compromise is being fabricated (see Walton and Macagno 2006). Within particular international settings, a threat to block trade may be conceived as quite appropriate for a negotiation dialogue, but not a threat to start a war.

Third, a compromise is based on a kind of trade. Any compromise is made possible by a distribution of material or other assets by which the participants, as it were, split the difference and this holds equally for compromises that settle differences of opinion. Underlying a compromise, there is some sort of exchange and before agreeing on any exchange, the parties must, at some point, decide upon or go along with a way of dealing with their difference of opinion as a problem of distributing or trading items, such as mutual promises to act or to refrain from acts in the future, thereby "commodifying" as it were their opinions. Of course, the parties are not required to renege on their deeply held convictions. All that is required for compromise to work is that the parties set up and acquiesce in some measure of commodification. Even if, for instance, a party considers human beings as God-ordained stewards of the earth, this party may-without abandoning this principle-for practical purposes go along with a policy that does not do full justice to its ideal of stewardship, in order to accommodate another, dissenting, party and make some political headway.

Fourth, the acceptance of a compromise implies commitments. When a negotiation dialogue results in a compromise consisting of the adoption of policy $\mathrm{P}$, each participant agreed to those actions that are required for $\mathrm{P}$ to get implemented. Next to having these action commitments, the parties can be expected to have agreed to particular propositions, and here we focus on these propositional commitments (see Walton and Krabbe 1995). The primary propositional commitment that an agreement on a compromise incurs is the proposition that all things considered, including the (real or alleged) circumstance of there being an irresolvable disagreement about what policy to pursue, $\mathrm{P}$ merits acceptance and implementation. Thus, if a compromise must, afterwards, be vindicated vis-à-vis political supporters, the appropriate vindication requires an appeal to the compromise's gains, as well as an excuse of the compromise's sacrifices in light of this irresolvable disagreement. When, however, consensus about the implementation of policy $\mathrm{P}$ results from a persuasion dialogue, each participant can certainly no less be expected to have become committed to P's meriting acceptance and implementation but within any subsequent defense of $\mathrm{P}$ vis-à-vis supporters an appeal to an underlying irresolvable disagreement would be out of order.

More precisely, the justification of a compromise towards those who are to endorse or ratify the deal plausibly requires a further commitment to support two theses. First, the justification requires upholding the thesis of eligibility: that a situation of endorsing (or ratifying) the compromise is to be preferred to a situation of rejecting it, arguing for instance that the gains will outweigh the sacrifices. 
Second, the justification requires upholding the thesis of optimality: that there is no compromise superior to the deal closed that all competing parties can be made to accept (see van Laar and Krabbe 2017b for our account of the justification of compromise; cf. Raiffa et al. 2002 on "efficient contracts").

In a properly conducted negotiation dialogue, the eligibility and the optimality of the resulting compromise is promoted by giving each party both the opportunity to make offers that are maximally advantageous for itself, and the opportunity to reject offers by competing parties that are not considered sufficiently advantageous. By tabling compromise proposals, the competing parties search for an outcome that each of them prefers to the status quo and that each of them accepts as the best result within reach given the existing differences of opinion amongst the competing parties (See van Laar and Krabbe 2016b, Section 4; 2017a for our account of the role of argument in fabricating a satisfactory compromise within a negation dialogue).

Consequently, a compromise does not compete for the same intellectual space as a standpoint about one's firstly preferred policy: Without contradiction one may defend policy $\mathrm{P}$ on substantial grounds as the preferred policy in those settings where we can disregard dissenting peers, as well as a contrary policy P' as the preferred policy in those setting where we do have to take into account that dissenting peers have to endorse the policy to be carried out.

Fifth, compromise may yield a resolution of actual or potential second-order disagreements. We saw that settling a difference of opinion by means of compromise is something quite different from realizing a resolution of this very difference of opinion because a compromise does not eliminate the initial disagreement. At the same time, we recognize a close tie between compromise and resolution, because a compromise plausibly implies the closure of two disagreements, whether actual or potential, both concerning the second-order problem of how to respond to the fact that the first order issue of what policy to pursue is irresolvable.

One kind of second-order disagreement is that about what method to select for dealing with the irresolvable first-order issue. A successful compromise typically implies a closure of any such second-order disagreement, because it typically presupposes a shared choice for negotiation as a method. In so-far as a second-order disagreement about the selection of a method is solved as a result of an exchange of argumentation that convinced the parties to opt for negotiation-for example by discussing the reasons for and against shifting to negotiation-the compromise can be seen as yielding a resolution of this (actual or potential) disagreement.

Another kind of second-order disagreement is that about precisely what compromise solution to select for dealing with the first-order problem. Given the selection of negotiation dialogue as a method, a compromise concludes any such further second-order disagreement. In so-far as a second-order disagreement about the selection of a compromise is eliminated as a result of an exchange of argumentation about the acceptability of the various offers, the compromise can be seen as yielding a resolution of that (actual or potential) disagreement.

Let us label the resolution of a second-order (or: first-order) disagreement a "second-order (or: first-order) resolution". Then we can say that a compromise may 
yield second-order resolutions of disagreements concerning how to respond to the fact that a first order disagreement about what policy to pursue is irresolvable. A compromise plausibly often indicates resolutions of differences of opinion, but these are second-order differences of opinion.

These insights can be illustrated as follows: Suppose, for instance, that you and I disagree on the issue: "Should we adopt your preferred policy Alpha or my preferred policy Beta?" Suppose further that we fail to realize a first-order resolution of this issue by means of a persuasion dialogue. If we opt to proceed by means of a negotiation dialogue, but do so only after considering the reasons for or against such a shift, then, apparently, all second-order disagreement about selecting a method for dealing with the irresolvable policy issue has been resolved. Let it further be the case that the negotiation dialogue results in the mutually acceptable compromise to settle for policy Gamma, and that the negotiation dialogue provides us with ample opportunity to critically assess the standpoint that indeed adoption of policy Gamma is acceptable in the circumstances at hand. Then this outcome yields a second-order resolution of the second-order issue "Does the selection of policy Gamma constitute an acceptable compromise within the current setting where you prefer policy Alpha and I prefer policy Beta?" Note that the resolution of such a second-order issue regarding a policy Gamma is often the result of a series of failed attempts to resolve similar issues regarding other possible compromises: the adoption of policies Delta, Epsilon, etc., such that by those failed attempts the parties obtain the information that is required for them to arrive at this particular second-order issue (regarding policy Gamma) that does admit of a (second-order) resolution (see van Laar and Krabbe 2016b, Section 4; 2017a).

Returning to the Fallacy of Middle Ground: this can be seen as a fallacy based on the illusion that a compromise equals a first-order resolution of the difference of opinion that prompted the parties to compromise. We distinguish two variants of this fallacy. Each of them can be diagnosed as a transgression of the argumentative norm that premises that are unacceptable to a sufficiently astute opponent-whether oneself in an internal dialogue or a different person in an external dialogue-should not be smuggled in by presenting them as a matter of course (cf. van Eemeren and Grootendorst 2004, starting-point rule, p. 193).

First, one may mislead oneself or others to accept a compromise Gamma as one's favorite policy choice, beguiled by the popular saying that the truth must be somewhere in the middle. The website named The Nizkor Project gives the following example of an alleged fallacy that seems to match with this first variant of the Fallacy of Middle Ground (albeit outside of any context where one would expect a compromise): "Some people claim that God is all powerful, all knowing, and all good. Other people claim that God does not exist at all. Now, it seems reasonable to accept a position somewhere in the middle. So, it is likely that God exists, but that he is only very powerful, very knowing, and very good. That seems right to me" (Nizkor Project 2016). This way of flawed reasoning may play a role in settings where a quarrel is used as evidence for the assumption that both are to blame, or where the vehement denial of the accused is taken to be a reason to suppose that, as a matter of fact, her acts could not have been as appalling as claimed by the prosecutor. 
The second variant could also be called the Fallacy of No Middle Ground: one may mislead oneself or others into refusing to subscribe to any compromise by confusing a compromise with a first order resolution and concluding that a violation of one's integrity would inevitably result (See Benjamin 1990, pp. 36-37). A politician may refuse to compromise on account of the impossibility to compromise on matters of principle, failing to see the importance of second-order reasons for compromises. However, a compromise can be entirely reasonable if it results from a negotiation dialogue in which the participants, possibly in addition to exerting some pressure, deliberate and reflect on the quality of the proposals (offers) and counterproposals (counteroffers). Of course, neither of these variants of the Fallacy of Middle Ground need be committed when one advocates or opposes a middle ground position. It is perfectly feasible to avoid the ploy of presenting compromise and (first order) resolution as equal, and though acknowledging the importance of this fallacy, the main message of our paper is that one may turn to compromise in a dialectically respectable way.

We conclude this section by discussing a possible objection. If there are reasons that convince the parties to shift from their persuasion dialogue to a negotiation dialogue, as well as further reasons that convince them to settle for a particular compromise, there exist reasons that could have been used successfully within the original persuasion dialogue to achieve a first-order resolution of a difference of opinion in favor of the very same policy that resulted from the negotiation dialogue (this objection, or at least a version of it, has been raised by Godden 2016). Consequently, one may reason, any well-considered compromise could also have been the outcome of a persuasion dialogue in which the parties are concerned merely with the best possible policy outcome based on the objective merits of the case. Thus, one may continue, well-reasoned compromises cannot be the focus of a Fallacy of Middle Ground (i.e. mistaken for first order resolutions), for the reason that there is, after all, a first-order resolution available in a persuasion dialogue about that compromise policy.

We disagree. First, it is feasible that these parties are unable to craft an agreed upon policy proposal in the context of a persuasion dialogue, yet are capable of finding such a compromise solution in the context of a negotiation dialogue. In that case, the first order resolution that would presumably be available would nevertheless be inaccessible for the parties, so that they would do better to negotiate. Second, agreement about a policy as an outcome of a negotiation dialogue is of a different kind than agreement about a policy as an outcome of a persuasion dialogue: a compromise is subscribed to on the basis of considerations that do not only have to do with the objective merits of the policy, but also with the social circumstance that mutual concessions are required to arrive at a shared policy. Each party would still prefer a different policy if it were to disregard (1) that the other side cannot be persuaded of one's favorite position and (2) that a lasting disagreement has highly negative effects. Therefore, the situation of a compromise is quite different than that of a first order resolution on the merits. But then, as we discussed above, there are second-order differences that get plausibly resolved when a compromise is reached. 
How does a compromise settle the difference of opinion, if the initial disagreement has not disappeared? It does so by the decision to move on, to take one's losses, and to implement the compromise through action. Thus, a compromise settles a difference of opinion about the original preferences, without resolving it. A Fallacy of Middle Ground can be committed by confusing the two kinds of results. But then, agreeing to compromise does not by itself constitute a Fallacy of Middle Ground: it can be the result of a dialectical procedure that is perfectly licit.

\section{Conclusion}

We have in this paper dealt with dialogue participants who shift from persuasion dialogue to negotiation dialogue, and who turn to compromise rather than resolution as a basis of further action. First, our dialectical reading of the considerations brought forward by May and Weinstock showed that within a persuasion dialogue, participants may dispose of and express good reasons for shifting towards a negotiation dialogue in which they cooperate to settle their difference of opinion by way of compromise. Splitting a difference of opinion may be a sensible idea, and the shift towards negotiation can be warranted, and made without committing the Fallacy of Bargaining. Second, we have found that a compromise that splits a difference of opinion is quite different from a resolution of a difference of opinion, and that splitting a difference of opinion does not imply any conceptual confusion between the two, let alone that a Fallacy of Middle Ground has been committed. On the other hand, we have seen that finding a compromise implies that potential second-order disagreements admit of a resolution.

In a sequel to the paper at hand (van Laar and Krabbe 2017a; see also van Laar and Krabbe 2016b, Section 4), we explain how arguments play a central role in most, if not all, negotiation dialogues, especially so if they aim at splitting differences of opinion. In our view, a negotiation dialogue made up from offers and counteroffers can be reconstructed as an interlocked series of argumentative moves. Each offer, counteroffer, countercounteroffer, and so forth, can be analyzed as being made up from two elements: an "expediency argument" in support of the standpoint that it is expedient for the interlocutor to accept the speaker's policy proposal, and a critical response to the premises of the expediency argument that was part of the offer in the preceding turn by the interlocutor (this latter element is absent in the very first contribution of the negotiation dialogue). In a successful negotiation dialogue, the critical responses step-wise steer the participants towards a successful final offer that happens to consist of an expediency argument based upon propositions that the interlocutor is willing to accept. In this way, we explain how compromise is in a special way connected to the resolution of a second-order disagreement concerning how exactly to "split the difference", thereby underwriting the possibility of a thoroughly argumentative process of compromise formation. Finally, we expect the argumentative analysis of negotiation to yield insights into the ways compromises can be challenged by those not present at the negotiation table and the ways they can be vindicated vis-à-vis those challenges (van Laar and Krabbe 2017 b). In these ways, we aim to develop a theory about the analysis and 
evaluation of argumentation in those settings where people are prepared to settle for a second-best solution.

Acknowledgements For critical comments we thank the audience of a presentation that included an earlier and shorter version of this paper and especially our commentator David Godden [11th OSSA conference, Windsor ON, May 2016; Godden (2016), van Laar and Krabbe (2016b, c)] and also our anonymous referees.

Open Access This article is distributed under the terms of the Creative Commons Attribution 4.0 International License (http://creativecommons.org/licenses/by/4.0/), which permits unrestricted use, distribution, and reproduction in any medium, provided you give appropriate credit to the original author(s) and the source, provide a link to the Creative Commons license, and indicate if changes were made.

\section{References}

Amgoud, Leila, and Henri Prade. 2006. Formal Handling of Threats and Rewards in a Negotiation Dialogue. In Argumentation in Multi-Agent Systems: Second International Workshop, ArgMAS 2005, Utrecht, The Netherlands, July 26, 2005: Revised Selected and Invited Papers, ed. Simon Parsons, Nicolas Maudet, Pavlos Moraitis, and Iyad Rahwan, 88-103. Berlin: Springer.

Benjamin, Martin. 1990. Splitting the Difference: Compromise and Integrity in Ethics and Politics. Lawrence: University of Kansas.

Godden, David. 2016. Commentary on Jan Albert van Laar \& Erik C.W. Krabbe "Splitting a difference of opinion". In Argumentation, Objectivity, and Bias: Proceedings of the 11th International Conference of the Ontario Society for the Study of Argumentation (OSSA), May 18-21, 2016, ed. Patrick Bondy and Laura Benacquista. Windsor: OSSA.

Krabbe, Erik C.W., and Jan Albert van Laar. 2007. About Old and New Dialectic: Dialogues, Fallacies, and Strategies. Informal Logic 27(1): 27-58.

Margalit, Avishai. 2010. On Compromise and Rotten Compromises. Princeton: Princeton University Press.

May, Simon Căbulea. 2005. Principled Compromise and the Abortion Controversy. Philosophy \& Public Affairs 33(4): 317-348.

Nizkor project. 2016. Fallacy: Middle Ground. Retrieved on March 3, 2016 from: http://www.nizkor.org/ features/fallacies/middle-ground.html.

Raiffa, Howard, John Richardson, and David Metcalfe. 2002. Negotiation Analysis: The Science and Art of Collaborative Decision Making. Cambridge: The Belknap Press of Harvard University Press.

van Eemeren, Frans H., and Rob Grootendorst. 2004. A Systematic Theory of Argumentation: The Pragma-Dialectical Approach. Cambridge: Cambridge University Press.

van Laar, Jan Albert, and Erik C. W. Krabbe. 2016a. Fair and Unfair Strategies in Public Controversies. Journal of Argumentation in Context 5(3): 316-348. https://doi.org/10.1075/jaic.5.3.04kra.

van Laar, Jan Albert, and Erik C. W. Krabbe. 2016b. Splitting a Difference of Opinion. In Argumentation, Objectivity, and Bias: Proceedings of the 11th International Conference of the Ontario Society for the Study of Argumentation (OSSA), May 18-21, 2016, ed. Patrick Bondy and Laura Benacquista. Windsor: OSSA. http://scholar.uwindsor.ca/ossaarchive/OSSA11/papersandcommentaries/128/.

van Laar, Jan Albert, and Erik C. W. Krabbe. 2016c. Reply to David Godden's commentary on "Splitting a difference of opinion". In Argumentation, Objectivity, and Bias: Proceedings of the 11th International Conference of the Ontario Society for the Study of Argumentation (OSSA), May 18-21, 2016, ed. Patrick Bondy and Laura Benacquista. Windsor: OSSA. http://scholar.uwindsor.ca/ ossaarchive/OSSA11/papersandcommentaries/64/.

van Laar, Jan Albert, and Erik C. W. Krabbe. 2017a. The Role of Argument in Negotiation. to be published. 
van Laar, Jan Albert, and Erik C. W. Krabbe. 2017b. Criticism and Justification of Negotiated Compromises. To be published in the proceedings of the 2nd European Conference on Argumentation (ECA), Fribourg 2017.

Visser, Marco. 2012. Wat hebben VVD en PvdA moeten inleveren? [What did the VVD and the PvdA have to sacrifice?] Trouw, October 29.

Walton, Douglas N. 1998. The New Dialectic: Conversational Contexts of Argument. Toronto: University of Toronto Press.

Walton, Douglas N., and Erik C.W. Krabbe. 1995. Commitment in Dialogue: Basic Concepts of Interpersonal Reasoning. Albany: State University of New York Press.

Walton, Douglas N., and Fabrizio Macagno. 2006. The Fallaciousness of Threats: Character and Ad Baculum. Argumentation 21: 63-81.

Weinstock, Daniel. 2013. On the Possibility of Principled Moral Compromise. Critical Review of International Social and Political Philosophy 16(4): 537-556.

Wells, Simon, and Chris Reed. 2003. Knowing When to Bargain: The Roles of Negotiation and Persuasion in Dialogue. In Computational Models of Argument: Proceedings of COMMA 2006, eds. P. E. Dunne and T. J. M. Bench-Capon, pp. 235-246. Frontiers in Artificial Intelligence and Applications, vol. 144. Amsterdam: IOS Press.

Wikipedia. 2016. Argument to Moderation. Retrieved on March 3, 2016 from: https://en.wikipedia.org/ wiki/Argument_to_moderation. 